\title{
DETERMINAÇÃO SOCIAL DA CÁRIE DENTÁRIA NA DENTIÇÃO DECÍDUA: APROFUNDANDO O CONHECIMENTO DA REALIDADE LOCAL*
}

\author{
SOCIAL STABLICH FOR THE TOOTH DECAY AT DECIDUA DENTITION: \\ A CAREFULLY EXAMINATION OF THE LOCAL REALITY \\ UNA FORMA SOCIAL DE LA CARIE DENTAL EN LA PRIMERA DENTICIÓN: \\ BUSCANDO CONOCER LA REALIDAD SOCIAL
}

\author{
Daniela Baena de Almeida Pontes** \\ Elizabeth Garzuze da Silva Araújo***
}

\begin{abstract}
* Este artigo é parte da monografia "Determinação social da cárie na dentição decídua: aprofundando o conhecimento da realidade local", orientada pela Prof. Elizabeth Garzuze da Silva Araújo, entregue em 2004, para obtenção do título de especialista em Saúde Coletiva, área de concentração em Saúde da Família, Universidade Federal do Paraná - UFPR.

** Cirurgiã-dentista. Especialista em Saúde Coletiva. Funcionária da Secretaria Municipal de Saúde - SMS de Curitiba.

*** Cirurgiã-dentista. Mestre em Educação pela UFPR. Professora aposentada do Departamento de Saúde Comunitária da Universidade Federal do Paraná.
\end{abstract}

RESUMO: Este trabalho visou identificar as causas do elevado número de cáries na dentição decídua, relacionado a padrões familiares e culturais, usando-se do método exploratório descritivo qualitativo, com estudo de caso, tendo uma amostra intencionalmente constituída com responsáveis pelas crianças com a doença cárie e que usavam aleitamento artificial, através de mamadeira, na consulta inicial no Programa do Bebê do Serviço de Odontologia da Unidade de Saúde São Miguel, em Curitiba. Realizaram-se visitas domiciliares e entrevistas abordando assuntos de saúde bucal. Como estas famílias já haviam sido atendidas pela equipe de saúde bucal, percebemos que as orientações iniciais, recebidas há cerca de dois anos, foram referidas quando reforçadas em outras relações sociais como escola, família. Assim, nos pareceu claro que a atuação dos profissionais apenas dentro da Unidade de Saúde, não trouxe efeito duradouro em saúde bucal, e uma ação social do profissional poderá trazer melhores resultados na saúde da comunidade.

PALAVRAS-CHAVE: Saúde da família; Saúde bucal; Cárie dentária.

ABSTRACT: This study seek to identified the causes of high numbers of caries at dedicua dentition, connecting familiar and cultural standards, the qualitative decriptive exploratory method, of study, and a intetionally composed sample with responsables, whose children have the caries diseases and were artificially nursered by feeding bottle, at the firt appointment at Babies Program of Odontology Health University os São Miguel - in Curitiba. Several home visits and interviews about mouth health issues. Since these families were cared by the mouth health team, we realized that the first instructions, provided up two years ago, were mentioned when reinvigorated at other social relations as the school, family. Thus it looks clear that the professionals actuation only inside of Health University, do not bring the long term mouth health effect, and a social action of the same professional may produce better results at the comminity health.

KEYWORDS: Family health; Oral health; Dental caries.

RESUMEN: El objetivo de este trabajo fue identificar las causas del alto numero de caries en la primera dentición, con relación a niveles familiares y culturales. El método usado fue explorador-descriptivo cualitativo, con estudio de casos, la muestra fue intencionalmente formada por responsables de niños con caries y que tomaban leche artificial en mamadera, en la primera consulta del Programa Odontológico del Niño en la Posta San Miguel, en Curitiba. Hubo visitas a los domicilios y entrevistas sobre el tema de la salud bocal. Estas familias ya habían sido atendidas por el Equipo de la salud bocal, notamos que las primeras orientaciones dadas a dos años atrás fueron comentadas al ser reforzadas en otras relaciones sociales, como escuela, familia, etc. Así siendo nos dejó claro que la actuación de los profesionales solamente dentro de la Posta, no tuvo un efecto durador en la salud bocal y una acción social del profesional puede traer mejores resultados en la salud de la comunidad.

PALABRAS-CLAVES: Salud de la familia; Salud bucal; Caries dental.

Recebido em: 05/08/2003

Aceito em: 17/11/2003
Daniela Baena de Almeida Pontes

Rua Parintins, 303 - Ap. 31

80320-270 - Curitiba - PR

E-mail: daniela@brasilservicetelecom.com.br 


\section{INTRODUÇÃO}

Esta pesquisa destinou-se a conhecer os determinantes dos altos índices da doença cárie na infância. Percebemos, na prática cotidiana da Unidade de Saúde São Miguel, que crianças com a doença, mesmo após consultas e orientações no Programa do Bebê, em alguns casos, tiveram a situação atual agravada. Consideramos ser necessário compreender a determinação social do processo saúde-doença, detectando os problemas estruturais geradores de doença, ou seja, onde eles realmente ocorrem, quais as influências culturais, econômicas, políticas e familiares. Compreendendo as doenças bucais como sendo determinadas socialmente, justifica-se o estabelecimento deste estudo regionalizado, que forneça elementos para a formulação de propostas viáveis e adequadas a uma realidade específica.

Acreditamos que na construção de uma ação integral à saúde e considerando o ser humano na sua totalidade, a saúde deve organizar os serviços para atender as necessidades de saúde da comunidade de forma contínua, desde a mais tenra idade.

Para identificar as necessidades de saúde de uma população, partimos do conceito de dialética da satisfação das necessidades de saúde de SANMARTÍN (1989), representada no esquema a seguir:

Quadro 1- Representação esquemática da dialética da satisfação das necessidades de saúde

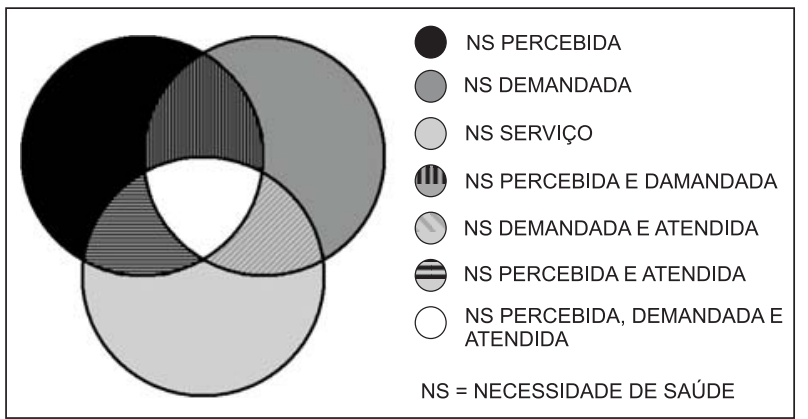

Fonte: Adaptado de Stotz, 2003

A partir desta representação esquemática, percebemos as múltiplas perspectivas a partir da qual o problema precisa ser situado, bem como sua complexidade. $^{1}$
Numa análise inicial, podemos afirmar que os profissionais de saúde normalmente são bem informados sobre as necessidades de saúde tecnicamente definidas e que os serviços estão organizados para atender. Pela experiência diária do trabalho, estes profissionais conhecem também, as necessidades de saúde demandadas, ou seja, aquelas pelas quais as pessoas procuram por atendimento, na Unidade de Saúde.

Mas as necessidades de saúde percebidas pelas famílias da área de abrangência, nem sempre chega ao conhecimento dos profissionais de saúde (área preta da representação esquemática). Muitas vezes estas são tratadas com receitas caseiras, benzedeiras, indicação de tratamento de conhecidos, sem gerar a demanda para o atendimento profissional. ${ }^{1}$

$\mathrm{Na}$ construção de um modelo de atenção integral à saúde, não podemos deixar de lado a identificação das necessidades de saúde percebidas pelas famílias, especialmente daquelas que não geraram demandas e para as quais os serviços não estão organizados para atender. Com a sua identificação, pode-se iniciar uma reflexão da prática dos serviços de saúde e planejar juntamente com a comunidade, propostas de ações nos serviços de saúde de maior efetividade (área branca, correspondente à interseção dos três círculos), de forma a atender também às necessidades de saúde percebidas pelas famílias. Esta aproximação da população permitirá iniciar uma reflexão sobre o que são necessidades de saúde, podendo buscar soluções para atender as necessidades que são demandadas nos serviços de saúde e que não são apenas necessidades de saúde.

\section{REVISÃO DE LITERATURA}

Por determinação social do processo saúdedoença podemos entender o modo específico pelo qual ocorre, numa dada população, o processo biológico de desgaste e reprodução, aparecendo um funcionamento biológico diferente, com conseqüência para o desenvolvimento regular das atividades 
cotidianas, isto é, o surgimento da doença. ${ }^{2}$ Colocada neste contexto a expressão saúde-doença foi um qualificativo empregado um determinado processo social, qual seja o modo específico de passar de um estado de saúde para um estado de doença e o modo recíproco. ${ }^{3}$

Nesta perspectiva, a situação de saúde estaria estreitamente vinculada com a vida cotidiana de indivíduos, familiares e populações. A vida cotidiana seria o espaço onde se manifestariam as articulações entre os processos biológicos e sociais que determinariam a situação de saúde; sendo também, portanto, o espaço privilegiado de intervenção da saúde pública e, por conseguinte de promoção de saúde. ${ }^{4}$

A pobreza, a ignorância, a falta de higiene não acontecem por acaso ou pela natureza "atrasada" das famílias brasileiras. Seria necessário compreender o processo histórico das desigualdades sociais.

A pobreza material (ou então a cultural), como também o desenvolver de uma atividade laboral insalubre, pouco qualificada e pouco satisfatória, favorece a ação de todos os fatores específicos de doenças e obstaculiza a adoção de medidas preventivas, tornando mais difícil o tratamento. $\mathrm{Na}$ pobreza permanece a causa principal das doenças e é um fator que está além das possibilidades de controle imediato da saúde. ${ }^{5}$

Quando pretendemos realizar ações efetivas em saúde, implica um envolvimento social para promover a tão falada qualidade de vida. Com todo o conhecimento existente a respeito dos fatores etiológicos, meios de prevenção e controle da cárie dentária, esta permaneceu como um grande problema de saúde.

Os dados de prevalência de cárie dentária nas pesquisas realizadas em 1996 pelo MS (Ministério da Saúde) nas capitais brasileiras, atribuindo ao Estado do PR (Paraná) um CPO-D (índice de dentes cariados, perdidos e obturados) médio de 2,23 foram comparados aos dados coletados, no mesmo período, pela SES-PR (Secretaria de Estado de Saúde) de 357 dos 371 municípios do Paraná, e foram analisados, encontrando um CPO-D médio para o Estado de 5,15 . No mesmo período, portanto houve um contraste elevado nos valores encontrados para o CPO-D médio, passando de baixa prevalência $(2,23)$ para alta $(5,15)$. Observou que municípios com menor porte, renda média mais baixa, menor porcentagem de domicílios ligados à rede de água e menor grau de escolaridade correlacionavam-se às maiores taxas de CPO-D, indicando a tendência de municípios com melhores condições de vida apresentarem menores índices do agravo. ${ }^{6}$

No município de Curitiba, a experiência do PSF (Programa Saúde da Família) iniciou-se em dezembro de 1991 no Centro de Saúde Pompéia, e em 1993, outro projeto, na Unidade de Saúde São José, contava com uma equipe de saúde bucal, embora, a nível nacional, só em 2000 ocorresse a incorporação das Equipes de Saúde Bucal. Esta prática nos pareceu mais adequada à problemática da saúde bucal coletiva, pois ao considerar o indivíduo inserido no seu meio social, seria possível atuar nos vários elos ou pontos da cadeia causal, não perdendo de vista o contexto mais geral, o funcionamento mais global da sociedade. Assim, os profissionais da saúde inseridos nesta nova proposta enfrentariam o desafio de ajustar o conhecimento técnico-científico de sua formação profissional à prática diária, comprometendose com a solução dos problemas de saúde, prevenção de doenças e promoção de qualidade de vida das famílias. Advogando em favor da parte da população mais diretamente prejudicada pelos "fatores ambientais e sociais".

O desafio para a odontologia é o de colocar os avanços da ciência a serviço de todas ou da maioria das famílias, estruturando um sistema de atendimento que seja adequado, aceito por pacientes e profissionais e que responda às necessidades de saúde da sociedade.

Os profissionais de saúde, juntamente com a população precisariam refletir sobre sua posição na sociedade, suas origens, procurando olhar com estranhamento a realidade, descortinando as falácias de verdades absolutas, da naturalização dos fatos. 
Assim, somente coletivamente, será possível produzir alguma mudança para sermos sujeitos de uma nova história com melhor qualidade de vida, que, conseqüentemente elevarão os níveis de saúde das famílias e da população.

\section{METODOLOGIA}

Para a presente pesquisa, utilizou-se o método exploratório descritivo qualitativo, através de estudo de caso.

A população-alvo da pesquisa foi a residente na área de abrangência da Unidade de Saúde São Miguel. Esta Unidade está inserida no Distrito Sanitário do Portão, um dos 8 Distritos da cidade de Curitiba. Neste Distrito, das 19 Unidades existentes, 15 possuem atendimento odontológico, $5 \mathrm{com}$ atendimento em Programa de Saúde da Família e 9 com atendimento básico. A Unidade de Saúde São Miguel é uma das unidades com atendimento básico.

Selecionamos a amostra a partir dos resultados do estudo realizado em 2002, nesta comunidade, com crianças de 0 a 6 anos. Os resultados revelaram uma taxa muito alta de crianças apresentando a doença cárie. Verificamos na amostra examinada que $57 \%$ das crianças tinham a doença aos 3 anos de idade.

Como a doença cárie é fortemente associada ao fator dieta, as crianças com a doença foram avaliadas quanto à forma de aleitamento no momento da consulta inicial. Através de respostas anotadas na ficha de anamnese, observamos que a maioria, ou seja, treze crianças, eram alimentadas por mamadeira com misturas, motivo pelo qual escolhemos este grupo para aprofundar a investigação do problema. Pretendíamos, desta forma, melhor conhecer o modo de vida destas famílias, a fim de elaborar e desenvolver ações de saúde mais efetivas na localidade.

Desta maneira, coerentemente com a delimitação teórica, renunciamos ao critério de "representatividade estatística". Assumimos, assim, a estratégia de privilegiar uma amostra intencionalmente constituída com os responsáveis pelas crianças com a doença cárie na dentição decídua. Por trabalharmos em Unidade de Saúde Básica, percebemos o caso do paciente, de modo eminentemente clínico, tratado individualmente com orientações aos responsáveis pela criança.

Ao consultarmos o cadastro geral da Unidade, verificamos que cinco pessoas da amostra inicial nunca moraram na área de abrangência da Unidade de Saúde. Para terem acesso a atenção à saúde, as pessoas criam mecanismos para serem atendidas, por meio do endereço de parentes moradores da área, ou mesmo o próprio endereço, e eram cadastradas normalmente nos programas de saúde bucal. Verificamos que duas moravam na área de abrangência da Unidade de Saúde Caiuá, uma, é da Cidade de Araucária, segundo funcionários da Unidade, e outra parece residir na Vila Verde. Somente uma criança era moradora da área, e não estava com o cadastro regularizado na Unidade, sendo localizada após conversas informais com Agentes Comunitários de Saúde. Assim, nesse primeiro momento, da amostragem inicial de treze pessoas, quatro foram excluídas.

Após a entrada em campo, das nove pessoas que, segundo o cadastro geral da Unidade de Saúde, ainda residiam na área de abrangência, duas não foram localizadas.

Assim, ficaram sete pessoas que foram convidadas a participar da pesquisa, onde nenhuma recusou o convite.

Às pessoas que aceitaram participar do trabalho, foi assegurado o caráter anônimo de suas identidades, bem como, a fidedignidade das respostas obtidas. Foram explicados os itens constantes no termo de consentimento livre e esclarecido, para que fosse assinado, ficando uma cópia com o entrevistado e outra com a pesquisadora, para ser arquivado. Solicitamos permissão para gravação da entrevista e posterior reprodução para digitação.

$\mathrm{Na}$ realização desse estudo foram respeitadas as normas da Resolução número 196/96 - Diretrizes 
e Normas Regulamentadoras de Pesquisa em Seres Humanos.

Este estudo foi aprovado pelo Comitê de Ética em Pesquisa do Setor de Ciências da Saúde da Universidade Federal do Paraná, em reunião do dia 03 de dezembro de 2003. Registro CPE/SD: 024.SI.024/03-11.

Após a elaboração do instrumento de coleta de dados, foi realizado um teste para sua validação, efetuando-se as adaptações necessárias. Os testes para validação do instrumento foram realizados no período de dezembro de 2003 a fevereiro de 2004.

O trabalho em campo, com a realização de visitas domiciliares e entrevistas, acompanhada de uma Agente Comunitária de Saúde foi desenvolvido no período de 01/03/2004 a 12/03/2004.

A coleta de dados foi feita pela própria pesquisadora, que identificou as famílias e procedeu a caracterização sócio-econômica. A entrevista foi conduzida de modo informal com perguntas e respostas, a fim de que os entrevistados se sentissem mais à vontade para expressar-se. O entrevistador controla a entrevista, porém quem dirige é o entrevistado. O trabalho profissional somente adquire sua real envergadura e transcendência quando nele coincide a investigação e a tarefa profissional, porque estas são as unidades de uma práxis que resguarda da desumanização a tarefa mais humana: compreender e ajudar outros seres humanos. ${ }^{7}$

O procedimento de análise de dados pode ser resumido nas seguintes etapas: análise prévia; categorização e reorganização; reflexão e reformulação ou análise final.

Esta separação em fases é para descrever o caminho do pensamento na reconstrução da realidade, não sendo fases estanques, mas um incessante movimento de leituras das falas e articulação com referencial teórico.

\section{RESULTADOS E DISCUSSÃO}

A proposta inicial de entrevistar as mães teve de ser modificada, visto que a maioria das mães ficam fora o dia inteiro, e a responsabilidade pelos cuidados com as crianças tem ficado a cargo das avós, tias e pais.

Tabela 1- Caracterização sócio-econômica das famílias, segundo tempo
de residência no bairro, e renda familiar mensal e per capita,
situação de saúde bucal (índice CEO-D) de famílias residentes
na área da U. S. São Miguel, Curitiba, PR - 2004.

Apesar das crianças situarem-se na faixa etária de 5, 6 anos, a maioria ainda alimenta-se através da mamadeira. Duas possuíam renda per capita inferior a 0,5 SM (salário mínimo), que é considerada insuficiente segundo alguns indicadores de renda. As famílias com renda inferior a 5 SM tiveram a situação atual agravada, comparada ao exame inicial. Outro estudo também demonstrou que crianças cuja renda familiar foi menor que $5 \mathrm{SM}$ tiveram 4,18 vezes mais chances de apresentar alta severidade de cárie, quando comparadas a famílias com renda superior a $5 \mathrm{SM}^{8}$

\section{ANÁLISE DE CATEGORIAS EMPÍRICAS}

Esta parte do trabalho se propõe a discutir a fala dos entrevistados, analisando separadamente as partes que se relacionaram aos objetivos específicos do estudo, não pretendendo esgotar o assunto, nem fechar à novos questionamentos, frente a complexidade da problemática de saúde bucal, que não se limita a análises superficiais, nem únicas.

$\mathrm{Na}$ categoria RAZÕES PARA ADOÇÃO DA MAMADEIRA em substituição ao aleitamento materno, segundo relato dos entrevistados, foi, principalmente, devido ao retorno ao trabalho (cinco casos), após o término da licença maternidade:"Ela mamava no peito, mas eu tinha que trabalhar, daí eu tive que tirar..." 
Outra pesquisa, em 2003, revelou que o trabalho foi um elemento dificultador ou impeditivo para a amamentação. A inadequação dos equipamentos sociais de apoio à mãe trabalhadora induz à interrupção da amamentação de forma precoce. ${ }^{9}$

Em VALOR ATRIBUÍDO À SAÚDE BUCAL foi destacada a aparência, sendo um fator presente em todas as falas. Outra grande preocupação apresentada foi com o mau hálito. A preocupação com a aparência foi expressa através de falas como ter dentes bonitos, deixar os dentes mais brancos, arrumar os dentes tortos (preocupação de 3 entrevistados), importantes para relações sociais como conversar, rir... Para uma entrevistada: "um dente feio assim, você sente vergonha de conversar, tipo... cárie vai dar um mau hálito na tua boca e você vai ficar com vergonha de falar com as pessoas (...) Um dente torto... você tem vergonha de sorrir, tem vergonha de falar com a pessoa."

Este fato foi encontrado em um trabalho de 1992, em que a aparência interferia nas relações sociais, pois uma aparência saudável refletia melhores condições para produzir. ${ }^{10}$

Analisando a CAUSALIDADE DAS DOENÇAS BUCAIS, verificamos que a percepção dos responsáveis sobre a doença cárie, mostrou-se bem indefinida, com respostas que mais pareciam dúvidas:

"A causa, assim, das cáries... doces, muito açúcar..."

"O cigarro... prejudica bastante os dentes ... acho que bebida... Os doces...eu mesmo tenho os dentes tudo estragado na frente. Por que? Por causa do cigarro... de doce..."

Aqui, percebemos outra contradição na sociedade capitalista: os entrevistados perceberam os doces como causadores da doença cárie, e mesmo assim, as crianças mantiveram uma dieta rica em açúcar: "A gente, que deu docinho, daí deu essa cárie, aquele pretinho sabe?"

Percebemos também a dificuldade das famílias em controlarem a alimentação em casa, pois uma alimentação saudável exige preparo e muitas vezes as crianças não comem. Um estudo datado de 2000 considerou que é notório que as maciças campanhas dos fabricantes de doces, promovendo seus produtos como naturais, socialmente aceitáveis e ligados a demonstrações de afeto, competem com grande vantagem sobre as mensagens educacionais a respeito do consumo de açúcar e da saúde bucal. ${ }^{11}$ Outro estudo, já citado, ${ }^{10}$ também destacou que a responsabilidade pelas más condições de saúde bucal é focalizada nos indivíduos, eximindo, assim, a prática odontológica e a própria sociedade de questionar o papel que desempenham na produção da doença.

A categoria OBTENÇÃO DE SAÚDE BUCAL esteve relacionada com a possibilidade de freqüentar os dentistas (mencionado em seis falas), e de praticar os cuidados individuais, escovando os dentes e praticando uma alimentação saudável, principalmente com a restrição de alimentos doces. Percebemos esta representação social também como uma introjeção da ideologia dominante de consumo capitalista, onde a saúde seria mais um bem a ser adquirido, seja através do consumo de serviços odontológicos ou do consumo de produtos de higiene bucal para realização dos cuidados de escovação. Segundo uma entrevistada: "É sempre estar procurando o dentista, né? A gente também tem que cuidar, tomar os cuidados em casa."

Assim, o fato das pessoas considerarem que a cárie dentária pode ser evitada pelo autocuidado e visitas ao dentista, evidencia que o aparecimento da doença e a busca pela saúde parece ser atribuição individual, sem qualquer conotação social. ${ }^{11}$

Em PERCEPÇÃO DA SAÚDE BUCAL FAMILIAR foi verificada outra contradição, quando os entrevistados consideraram favorável a saúde bucal da família, relacionando-a apenas ao fato dos dentes não incomodarem ou terem recebido algum atendimento odontológico. Para uma das entrevistadas: "Ela tem os dentes bons. Só a mãe tem problema de dor nos dentes... só que ela tem os dentes tudo bom. Quando dói, ela vai sempre no postinho, daí ela trata e melhora." 
Este fato já foi relatado, em outro estudo de 2001 , onde a maioria das pessoas via sua condição de maneira favorável, mesmo em condições clínicas não satisfatórias, provavelmente porque os critérios com que as pessoas avaliam sua condição bucal são diferentes dos do profissional. ${ }^{12}$ Os profissionais avaliam pela ausência de doença, e as pessoas pela ausência de dor.

\section{Em PERCEPÇÃO SOBRE A PRÁTICA} ODONTOLÓGICA, os entrevistados reclamaram da dificuldade de acesso, sendo que uma entrevistada refere: "É muita gente... às vezes você não consegue ser atendido." Outra também se queixou: "Quando eu fui lá não atenderam, eu até agora não consegui... Ah, eu fiquei nervosa, né? É passa pela triagem, espera e não atende... Aí para ir lá de novo, tem que passar pela triagem... não é assim, de novo?" Há uma grande divergência entre o número total da população a ser assistida pela Unidade de Saúde e o número de atendimentos/recepções, comparadas a outras Unidades de Saúde básicas do Distrito. Assim, a grande demanda nos serviços desta Unidade, cuja organização está orientada para o atendimento a uma população relativamente menor, vem gerando insatisfação nos usuários, que não têm suas necessidades de saúde atendidas. Esse tipo de assistência vem reforçar conceitos de que a procura por atendimento odontológico deve se dar em momentos de dor ou de urgência, não se preocupando com prevenção, manutenção e promoção de saúde, fato este prevalente nas famílias brasileiras.

Para um dos entrevistados a percepção sobre a prática odontológica apareceu como geradora de problemas na saúde bucal da família: "O problema eu acho é que trata bem eles, esses 'dentão' que sai, trata muito bem dele e acho que daí ele não cai...daí o outro vem, por cima por baixo, sei lá que tipo que saí daí...deve ser isso não sei. 'Os dentes' dele era tudo obturadinho, era coisa mais linda a boca daquele piá, (pensa)... daí os dentes em vez de cair, não caiu e veio outro por cima daqueles. Aqui, ele tem dois dentes sobrando para cima."
O tratamento odontológico, ao manter os dentes saudáveis na boca, neste caso, acarretou um dano estético de apinhamento dos dentes anteriores, gerando uma grande preocupação para a família que depende dos cuidados de atenção da Saúde Pública. Restou, assim, um incômodo pelo fator estético e pela impossibilidade financeira de fazerem um tratamento especializado, neste caso, na área de Ortodontia. Criar uma nova cultura não significa apenas fazer individualmente descobertas 'originais'; significa também; e sobretudo, DIFUNDIR CRITICAMENTE VERDADES JÁ DESCOBERTAS, 'socializá-las', por assim dizer; transformá-las, portanto, em base de ações vitais. ${ }^{13}$

Apesar de todas as dificuldades, alguns entrevistados reconheceram os avanços da Odontologia, na facilitação do acesso: "Eu me lembro que no tempo de infância (pensa) a minha mãe... quando nós tínhamos os nossos 8,9 ou 10 anos. Nós morávamos lá no Boqueirão, ela já se preocupava com a gente... cuidar dos dentes, uma preocupação dela... Nós acordávamos 3 horas da manhã, sabe, e lá íamos nós, às 4 e meia, 5 horas nós estávamos lá na fila da Cândido Lopes, sabe...onde tinha dentista antigamente lá.. ."

Sobre o APRENDIZADO EM SAÚDE BUCAL, uma entrevistada relatou: "Eu aprendi na escola, né? a escovar os dentes. A escola passa bastante coisa também...A L. já aprendeu a escovar os dentes, foi eu né? (ri) quem ensinei, é mais eu do que a mãe. A S. também fui eu. Antigamente não tinha dentista nos postos né? Não tinha não ... aqui na vila não tinha."

As concepções que os sujeitos possuem de saúde, inclusive bucal, são construídas no dia a dia das pessoas, no ambiente familiar, na escola, nas Unidades de Saúde, além da influência inegável dos meios de comunicação em massa, como a televisão.

Desta forma, a representação social sobre saúde-doença depende da relação que o ser humano estabelece com o ambiente e com os outros seres. Esta percepção baseia-se em geral na informação e no conhecimento disponível, sendo construída nas 
relações que estabelece no seu dia a dia. É importante ressaltar que esta abordagem de conhecer a percepção dos entrevistados sobre saúde, é apenas um elemento na busca da melhoria do estado de saúde de uma comunidade, sendo responsabilidade tanto individual como social. Este conhecimento permite uma abordagem mais efetiva e democrática, com a participação das famílias nas questões de saúde na construção de melhores condições de vida, e conseqüentemente de saúde.

\section{CONSIDERAÇÕES FINAIS}

Este estudo permitiu um olhar aprofundado sobre o assunto, para melhor conhecer quem é o ser humano que procura por nosso atendimento, só percebido por nós profissionais de Unidade de Saúde básicas, em atendimentos pontuais durante uma triagem, ou em um atendimento individualizado na cadeira.

Ao realizarmos visitas domiciliares, percebemos melhor a realidade desta população, tão distante da nossa. Conhecendo as pessoas no ambiente onde vivem, podemos iniciar o resgate da totalidade do ser humano, que não é apenas uma boca com doenças como a cárie, ou a gengivite. Tem toda uma estrutura social que determina que aquela condição apareça naquela boca... e que fica tão oculta ao vermos simplesmente a pessoa deitada na cadeira odontológica e de boca aberta, sem ao menos poder dialogar com o profissional durante 0 tempo de atendimento.

É necessário compreender o sentido mais amplo da problemática da saúde coletiva, como meta a ser conquistada, a qual exige um compromisso do profissional da saúde com as famílias e com a sociedade, visando elevar a sua consciência sanitária na luta por melhores condições de vida que, conseqüentemente, elevarão os níveis de saúde populacional.

O compromisso do profissional de saúde com a sociedade requer, não apenas, uma atuação social como cuidador das doenças, mas de promover saúde, educando para a saúde e instrumentalizando as famílias com recursos para que possa lidar com situações de desequilíbrio durante o processo saúdedoença, o que corresponde ao empoderamento das populações na prática de promoção de saúde. Este empoderamento só será obtido elevando-se o nível de consciência destas famílias, para que elas passem do senso comum para o senso filosófico, percebendose como sujeitos de sua história, para então poderem agir como tal.

A problemática de saúde bucal é muito ampla, para que possa ser solucionada apenas em ambientes de Unidades de Saúde. Assim, parece-me que a proposta do PSF, ao inserir os profissionais de saúde no meio social, criando vínculos com a comunidade e articulando apoio intersetorial, avança na construção para uma Odontologia Integral. Uma atuação destes profissionais na sociedade permite troca de experiências e mudança na percepção das pessoas sobre a saúde, concebendo-a como um direito de fato, e não um bem dado pelo atendimento profissional.

Acreditamos que uma ação social dos profissionais de saúde resultará em melhores resultados na saúde das famílias. Entendendo por ação social as atividades desenvolvidas em parceria com outros profissionais, tanto da saúde, como da educação e outros trabalhadores, para buscar mudanças sociais e ambientais que afetam a saúde coletivamente, buscando ações colaborativas em todos os níveis da sociedade, propondo políticas públicas saudáveis, para que a problemática de saúde bucal deixe de ser responsabilidade apenas individual para tornar-se social, ou seja, um problema social coletivo.

\section{REFERÊNCIAS}

1 Stotz EN. Os desafios para o SUS e a educação popular: uma análise baseada na dialética da satisfação das necessidades de saúde. Varal de Textos: políticas e sistemas de saúde. [on line] Disponível em: http:// www.redpopsaude.com.br. (09 out. 2003).

2 Laurell AC. A saúde-doença como processo social. In: Nunes ED, organizador. Medicina social: aspectos históricos e teóricos. São Paulo: Global Ed.; 1983. p. 133-58. 
3 Rouquayrol MZ, Goldbaum M. Epidemiologia, história natural e prevenção de doenças. In: Rouquayrol MZ, Almeida Filho N. Epidemiologia \& Saúde. 5. ed. Rio de Janeiro: MEDSI; 1999. p.15-30.

4 Ferreira JR, Buss PM. O que o desenvolvimento local tem a ver com a promoção de saúde? In: Zancan $L$, Bodstein R, Marcondes WB, organizadores. Promoção de saúde como caminho para o desenvolvimento local: a experiência em Manguinhos- RJ. Rio de Janeiro: ABRASCO/FIOCRUZ; 2002. p. 15-37.

5 Berlinguer G. Ética da saúde. São Paulo: Hucitec; 1996. p.38-9.

6 Baldani MH, Narvai PC, Antunes JLF. Cárie dentária e condições sócio-econômicas no Estado do Paraná, Brasil, 1996. Cad Saúde Públ [on line] 2002; 18:755-62. Disponível em www.scielo.br (01maio2003).

7 Bleger J. Temas de psicologia: entrevista e grupos. São Paulo: Martins Fontes; 1998. p.1-19.
8 Peres KGA, Bastos JRM, Latorre MRDO. Severidade de cárie em crianças e relação com aspectos sociais e comportamentais. Rev Saúde Públ [on line] 2000; 34:4028. Disponível em: www.fsp.usp.br/rsp. (15set2003).

9 Ramos CV, Almeida JAG. Alegações maternas para o desmame: estudo qualitativo. J Pediatr 2003; 79(5):385-90.

10 Bernd B et al. Percepção popular sobre saúde bucal: o caso das gestantes do Valão. Saúde deb 1992; 34:33-9.

11 Unfer B, Saliba O. Avaliação do conhecimento popular e práticas cotidianas em saúde bucal. Rev Saúde Públ 2000; 34(2): 190-5.

12 Silva SRC, Castellanos Fernandes R A. Autopercepção das condições de saúde bucal por idosos. Rev Saúde Públ [on line] 2001; 35(4):349-55. Disponível em: http://www.fsp.usp.br/rsp. (15set2003).

13 Gramsci A. Concepção dialética da história. Tradução de Carlos Nelson Coutinho. 8 ed. Rio de Janeiro: Civilização Brasileira; 1989. 